\section{Annual Under-vine Cover Crops Did Not Impact Vine Growth or Fruit Composition of Mature Cool-climate 'Riesling' Grapevines}

\author{
Lindsay M. Jordan ${ }^{1,2}$, Thomas Björkman, and \\ Justine E. Vanden Heuvel
}

AdDitional InDEx words. wine, northeastern United States, Finger Lakes, herbicide, vineyard, sensory, weeds, buckwheat, annual ryegrass

SUMMARY. In the cool and humid climate of the northeastern United States, vegetation is typically maintained between the rows of wine grape (Vitis vinifera) vineyards, but the area directly beneath vines is conventionally kept bare using herbicides or cultivation, to reduce competition for water and nutrients. Yet with rising concerns of herbicide resistance, environmental contamination, and soil erosion, alternatives to maintaining bare ground in vineyards should be considered. In warmer and more arid climates, using cover crops as an alternative to bare soil has sometimes resulted in reduced vine growth and yields. In more cool and humid climates, like in the northeastern United States, where conditions can promote excessive vine growth, replacing bare soil with under-vine cover crops was hypothesized to improve vine growth characteristics and fruit quality from reducing excessive vigor. This study compared three annual under-vine cover crops of resident vegetation (RES), buckwheat (BW) (Fagopyrum esculentum), and annual ryegrass (ARG) (Lolium multiflorum), planted in the 1 -m-wide strip directly under vines at the start of each growing season, against the conventional weed-free under-vine row maintained with glyphosate. The experiment was established in 2011 and repeated in 2012 and 2013 in a 20-year-old block of 'Riesling' wine grapes (clone 198 on S04 rootstock) in a commercial vineyard in the Finger Lakes region of New York State. Harvested grapes were fermented in duplicate using standard white wine procedures. Among the four under-vine treatments, no significant differences were found in measures of vegetative growth, yield, petiole nutrient concentrations at veraison, or predawn and midday stem water potentials. Under-vine treatments were not found to significantly affect soil organic matter, aggregate stability, and nutrient concentrations. Juice characteristics were also not significantly different among treatments. In this study, the mature vines in this rain-fed 'Riesling' vineyard likely had a welldeveloped and extensive rooting system that was able to overcome any competition effects for water or nutrients from the comparatively shallow root systems of the annually established cover crops. Without any induced competition in the conditions of this study, under-vine cover crops had no effects on vine growth, yield, or juice characteristics when compared with conventional herbicide use in the under-vine row. When multidimensional scaling (MDS) analysis was used to determine differences in aroma among wine treatment replicates, treatments were found to significantly impact the perceived aromatic properties of the wines, even though no measures of growth or juice characteristics were affected. Using under-vine vegetation may be a viable alternative to conventional herbicide use for vineyard floor management in mature wine grape vineyards in cool and humid climates. maintain bare soil, but cultivation can encourage soil erosion in vineyards (Martinez-Casanovas and SanchezBosch, 2000). Using cover crops in under-vine rows could offer a sustainable alternative to maintaining bare ground in vineyards.

In the cool and humid Finger Lakes region of the northeastern United States, frequent rainfall throughout the growing season contributes to wet conditions that promote detrimental, vigorous vine growth. Excessive vine growth contributes to deleterious canopy shading and reduced fruit quality (Smart et al., 1990). When vine growth is vigorous, the balance between vegetative and reproductive growth can be shifted away from the ideal ratio ranging between 4 and 10 for high-quality wine production (Kliewer and Dokoozlian, 2005). To manage undesirable vigor, reduce disease incidence and to improve fruit and wine quality, growers use costly canopy management practices including hedging, leaf removal, and shoot, lateral shoot, and cluster thinning, which treat the symptoms of excessive vigor without addressing the cause of the problem.

Introducing competition through the use of under-vine cover crops could be beneficial in viticultural regions that receive ample rainfall during the growing season, which can subsequently promote excessive vegetative growth of vines. Cover crop use in the interrows of wine grape vineyards outside of the northeastern United States have been found to reduce measures of vine vigor, including shoot and lateral shoot growth, leaf layers in the canopy, individual leaf area, and pruning weights (Morlat and Jacquet, 2003; Reynolds et al., 2005; Tesic et al., 2007; Wheeler et al., 2005) and have
$\mathrm{T}$ raditionally, the soil directly beneath vines in wine grape vineyards is kept vegetation free to eliminate competition for water and nutrients. In the northeastern United States, bare soil is typically maintained beneath vines in vineyards with cultivation or herbicide (Wolf, 2008). Repeated herbicide use risks resistance development (Holt, 1992) and herbicide runoff from vineyards can cause environmental contamination (Landry et al., 2006). To reduce the risks of using herbicides, growers may instead use repeated cultivation under vines to

\begin{tabular}{llll}
\hline $\begin{array}{l}\text { Units } \\
\text { To convert U.S. to SI, } \\
\text { multiply by }\end{array}$ & U.S. unit & SI unit & $\begin{array}{l}\text { To convert SI to U.S., } \\
\text { multiply by }\end{array}$ \\
\hline 10 & $\%$ & $\mathrm{~g} \cdot \mathrm{L}^{-1}$ & 0.1 \\
29.5735 & $\mathrm{fl} \mathrm{oz}$ & $\mathrm{mL}$ & 0.0338 \\
0.3048 & $\mathrm{ft}$ & $\mathrm{m}$ & 3.2808 \\
2.54 & inch $(\mathrm{es})$ & $\mathrm{cm}$ & 0.3937 \\
25.4 & inch(es) & $\mathrm{mm}$ & 0.0394 \\
6.4516 & inch & $\mathrm{cm}^{2}$ & 0.1550 \\
0.4536 & $\mathrm{lb}$ & $\mathrm{kg}$ & 2.2046 \\
1.1209 & $\mathrm{lb} / \mathrm{acre}$ & $\mathrm{kg} \cdot \mathrm{ha}^{-1}$ & 0.8922 \\
1.6093 & mile $(\mathrm{s})$ & $\mathrm{km}$ & 0.6214 \\
28.3495 & $\mathrm{oz}$ & $\mathrm{g}$ & 0.0353 \\
7.4892 & $\mathrm{oz} / 100 \mathrm{gal}$ & $\mathrm{g} \cdot \mathrm{hL} \mathrm{L}^{-1}$ & 0.1335 \\
1 & $\mathrm{ppm}$ & $\mathrm{mg} \cdot \mathrm{L}^{-1}$ & 1 \\
0.0069 & $\mathrm{psi}$ & $\mathrm{MPa}$ & 145.0377 \\
$\left({ }^{\circ} \mathrm{F}-32\right) \div 1.8$ & ${ }^{\circ} \mathrm{F}$ & ${ }^{\circ} \mathrm{C}$ & $\left({ }^{\circ} \mathrm{C} \times 1.8\right)+32$
\end{tabular}


brought vine balance and yield growth measures closer to ideal standards (Monteiro and Lopes, 2007; Sicher et al., 1993). In the humid midAtlantic region of the United States, perennial grass under-vine covers reduced vine growth (Giese et al., 2014) and improved the cluster and leaf exposure flux availabilities (Hatch et al., 2011). Introducing under-vine cover crops in cool-climate regions could reduce or eliminate herbicide use in vineyards and potentially alleviate excessive vigor, reducing the need for canopy management practices.

To explore the potential of replacing bare ground, under-vine cover cropping must be adapted to the conditions in the northeastern United States. In the northeastern United States, hilling up soil over the graft unions of vines is necessary to reduce the risk of complete scion death during freezing winters (Wolf, 2008). Growers mound soil from the under-vine row around the graft union for insulation in the fall, ensuring the survival of scion budwood. The soil is then plowed back down in the under-vine row at the start of the growing season. These two intensive cultivation operations in the under-vine row are repeated annually, which prohibit the establishment of the previously studied perennial vegetation covers and create specific conditions for vineyard floor management not seen in other regions. Very few studies have specifically examined the use of annual cover crops planted directly beneath vines. The only two reports from the northeastern United States where the hilling up practice occurs exclusively examined the red wine grape 'Cabernet franc' (Centinari et al., 2015; Karl, 2015), but with inconsistent results. Annual under-vine cover crops reduced vine

\footnotetext{
Department of Horticulture, New York State Agricultural Experiment Station (NYSAES), Cornell University, Geneva, NY 14456

This work was partially supported by Ronni Lacroute Dean's Discretionary Fund for Enology and Viticulture at Cornell University.

The authors thank John Wagner at Wagner Vineyards for providing and maintaining the vineyard experimental site, Steve Lerch for technical support, Hans Walter Peterson and Mike Colizzi for assistance during harvest, Jim Meyers for his help at harvest and with compiling the MDS analysis, Francoise Vermeylen from the Cornell Statistical consulting unit for statistical analysis, and Anna Katharine Mansfield for consultation on winemaking practices.

${ }^{1}$ Present address: University of California Cooperative Extension, 328 South Madera Avenue, Madera, CA 93637

${ }^{2}$ Corresponding author. E-mail: lmjordan@ucanr.
} edu. growth and yields as observed in the study by Karl (2015), but were not found to have any effect in the study by Centinari et al. (2015). There has been no research on how under-vine cover crops may affect white wine grape production systems, including 'Riesling' vineyards, which are very important for commercial wine production in the northeastern United States.

The objective of this research was to determine if under-vine cover crops induced sufficient competition to impact 'Riesling' wine grapes in the cool and humid northeastern U.S. climate. It was hypothesized that given the moisture-rich growing conditions, replacing bare soil with cover crops beneath vines would not have a serious impact to vine health, but improve vine growth and fruit quality from reducing excessive growth. Annual cover crops of BW and ARG were planted and RES was allowed to grow beneath 'Riesling' vines, and these treatments were compared with bare ground maintained with herbicide applications.

\section{Materials and methods}

EXPERIMENTAL SETUP. The experiment was established in a commercial, nonirrigated 'Riesling' wine grape vineyard in Lodi, NY, on the lower east side of Seneca Lake (lat. $42.57^{\circ} \mathrm{N}$, long. $76.86^{\circ} \mathrm{W}, 260 \mathrm{~m}$ elevation). The soil was a Honeoye silt loam soil, fine-loamy, mixed, semiactive, mesic Glossic Hapludalfs (U.S. Department of Agriculture, 2013). 'Riesling' vines (clone 198 on SO4 rootstock) were planted in 1995 on $9 \times 6$-ft spacing. Vines were trained in a Scott Henry system and shoots were positioned vertically on 3 - and $3.3-\mathrm{ft}$ horizontal fruiting wires for the lower and upper fruiting zones, respectively. The specific portion of the vineyard block was identified for under-vine treatment establishment because the area produced commercially acceptable yields, but there was excessive, unwanted vegetative growth. Four under-vine treatments were established in a randomized complete block design across four rows of the vineyard block, and each treatment was replicated four times. In 2011 and 2012, an experimental unit had three panels (12 vines), with the middle panel (four vines) being used for data collection. In 2013, treatments were only established on the data collection panels because of an herbicide application error in the buffer vine zone adjacent to the experimental units, so data were collected from the internal two vines with the outer vines of the panel serving as buffer vines.

Treatments were established annually on the former herbicide strip, which was $\approx 1 \mathrm{~m}$ in width. The RES treatment was allowed to emerge naturally throughout the season. When vines reached the phenological stage of veraison $(50 \%$ of berries softening and starting to turn translucent) and at harvest, the species present in the under-vine rows were identified. For planting the two other cover crop treatments, soil in the former herbicide strip beneath vines was cultivated by hand using a garden hoe. Cover crops were seeded at a much higher than normally suggested rate to ensure a strong and uniform stand established annually in the under-vine row. In each year of the study, ARG was hand-seeded at $70 \mathrm{lb} /$ acre in the second week of May and $\mathrm{BW}$ was hand-seeded at $350 \mathrm{lb} /$ acre in the last week of May (Ernst Seed Co., Meadville, PA) in the 1-mwide strip beneath vines. Soil was then gently raked over seeds in all treatments. The control (CON) treatment was treated with $2.75 \mathrm{lb} /$ acre a.i. glyphosate (Roundup ${ }^{\circledR}$ Power Max; Monsanto, St. Louis, MO), when weed growth would normally be treated with a contact herbicide in commercial production, on 4 June 2012, 3 June 2013, and 2 July 2013, when weed emergence was noted in the control plots. Emergence during the rest of the growing season was insufficient to require another application for control. In accordance to standard disease and canopy management practices in the region, vines were shoot-thinned to 20 primary shoots per linear meter of canopy row in the first week of June each year, preferentially removing all secondary and non-fruitful shoots. Vegetative growth was managed throughout the season with vertical shoot positioning and hedging by the grower. Vineyard interrows were composed of established RES and mowed throughout the growing season. Fertilization occurred via foliar applications of micronutrients at bloom by the grower across the entire block. Vines were in good health and 
managed according to standard practices for wine grape plantings in the Finger Lakes region, including a pesticide program to control pests and diseases appropriate to the region (Wolf, 2008). Climate data were sourced from the Network for Environment and Weather Applications from a weather station (New York State Integrated Pest Management Program, 2014 ) within $3 \mathrm{~km}$ of the research site (lat. $42.54^{\circ} \mathrm{N}$, long. $76.87^{\circ} \mathrm{W}, 219 \mathrm{~m}$ elevation).

SoIL AND PETIOLE ANALYSIS. Soil was collected in accordance with the Cornell Soil Health Test sampling protocol (Gugino et al., 2009) after harvest in the final year of the study (19 Oct. 2013). Within each experimental unit, three random soil samples of $\approx 250 \mathrm{~mL}$ were taken from the top $20 \mathrm{~cm}$ of the soil from the under-vine row, pooled, thoroughly mixed, and dried at $50{ }^{\circ} \mathrm{C}$ overnight before being submitted for analysis at the Cornell Nutrient Analysis Laboratory (Ithaca, NY) for Morgan extractable nutrient content analysis using inductively coupled argon plasma atomic emission spectrophotometry [ICP-AES (Spectro; Ametek Materials Analysis Division, Kleve, Germany)], organic matter content from loss on ignition, and wet aggregate stability according to the Cornell Soil Health Test (Gugino et al., 2009). For petiole testing, from within each experimental unit, 100 petioles in 2011 and 2012 and 60 in 2013 were cut from healthy, recently mature leaves located on the top half of primary shoots at veraison. Samples were gently washed in a mild soap solution, rinsed with deionized water, stored in paper bags, and dried at $90{ }^{\circ} \mathrm{C}$ for $\mathrm{l} \mathrm{h}$. Samples were submitted to the Cornell Nutrient Analysis Laboratory for Dumas combustion analysis (vario MACRO cube; Elementar Americas, Mount Laurel, NJ) of carbon and nitrogen and dry ash digestion in a $10 \%$ hydrochloric acid matrix, analyzed by ICP-AES (Spectro) for aluminum, boron, calcium, copper, iron, potassium, magnesium, molybdenum, manganese, sodium, potassium, and zinc.

VegetATIVE GROWTH MEASURES. In early June of each growing season, four randomly selected fruitful shoots per vine from each experimental unit were flagged. From that time onward, the shoot lengths were measured from the base of the shoot to the shoot tip using a flexible measuring tape throughout the growing season until the primary shoot tip was damaged or hedged in late July. At $\approx 50 \%$ veraison (20 Aug. 2011, 15 Aug. 2012, and 28 Aug. 2013), the internodes of four randomly selected shoots per vine in each experimental unit were measured above their first fully developed nodes using electronic calipers $(0.5-\mathrm{ft}$ metric and SAE caliper; Kolbat, Mooresville, NC). To account for oval shapes, two measurements, across the larger and smaller diameter of each shoot width, were taken and averaged for each reported cane diameter data point. Pruning weights of the dormant canes, which had been hedged during the growing season, were taken within 2 weeks of commercial pruning operations in late March each year. Each vine within an experimental unit was dormant pruned to four 10-bud fruiting canes with renewal spurs, and the prunings were weighed on a per-vine basis with a hanging scale accurate to $0.01 \mathrm{~kg}$ (model SA3N340; Salter Brecknell, Fairmont, $\mathrm{MN}$ ).

ENHANCED POINT QUADRAT ANALYSIS. At veraison, the canopy architecture was quantified using the point quadrat analysis (PQA) method (Smart and Robinson, 1991) and the enhanced point quadrat analysis (EPQA) functions (Meyers and Vanden Heuvel, 2008). For each vine within each experimental unit, canopy probe insertion measurements were taken every $20 \mathrm{~cm}$ along the upper and lower horizontal fruiting zones of the canopy and the leaf and cluster layers quantified at that point. Photosynthetic photon flux measurements, to quantify canopy light interception, were taken within $2 \mathrm{~d}$ of PQA measurements using a ceptometer (AccuPAR LP-80; Decagon Devices, Pullman, WA) within $1.5 \mathrm{~h}$ of solar noon on a clear day. For each data panel, the intracanopy photon flux was measured by holding the ambient flux sensor in the unshaded middle row, while placing the ceptometer parallel to the row within the center of the canopy in the fruiting zone at the height of each fruiting wire. Ten measurements were averaged for calculating canopy light interception characteristics for each vine using EPQA (Meyers and Vanden Heuvel, 2008).

Vine Water potential. Predawn leaf water potential $\left(\Psi_{\text {predawn }}\right)$ was measured monthly during the growing season. Measurements were taken between 0330 and $0500 \mathrm{HR}$ using a Scholander pressure chamber (Plant Water Status Console 3000; Soil Moisture Equipment Corp., Santa Barbra, CA). Two healthy, fully developed leaves from the top half of primary shoots were selected from different vines within an experimental unit and enclosed in a $250-\mathrm{cm}^{2}$ plastic bag. They were then cut at the petiole with a razor blade and inserted into the pressure chamber within $10 \mathrm{~s}$. The chamber was then pressurized with nitrogen gas at about a rate of $0.1 \mathrm{MPa} \cdot \mathrm{s}^{-1}$ until xylem sap exuded from the cut petiole. This balance pressure was multiplied by -1 to get the $\Psi_{\text {predawn }}$ of the vine. Midday stem water potential $\left(\Psi_{\text {midday }}\right)$ measurements were taken throughout the growing season within $1.5 \mathrm{~h}$ of solar noon using the pressure chamber described above. Healthy, well-exposed, fully developed leaves from the top half of primary shoots were enclosed within aluminum foil covered $250-\mathrm{cm}^{2}$ plastic bags for $\mathrm{l} \mathrm{h}$ before $\Psi_{\text {midday }}$ measurements were made. Balance pressure was then determined as for $\Psi_{\text {predawn }}$.

H A R V E S T A N D J U I C E CHARACTERISTICS. At harvest, the grapes from each experimental unit were hand harvested either $1 \mathrm{~d}$ before or on the day of commercial harvest (5 Oct. 2011, 22 Sept. 2012, and 3 Oct. 2013), as determined by the cooperating grower. The total number of clusters per vine was counted and the cumulative cluster weight per vine was measured at harvest using a hanging scale (model SA3N340), and subsequent average cluster weight calculated from these values. Ravaz index values were calculated each season on a per-vine basis within the experimental unit, by dividing the harvest yield data by the subsequent pruning weights taken in the winter of dormant canes. For each experimental unit, two 100-berry samples were randomly collected and weighed using a balance with $\pm 0.001 \mathrm{~g}$ accuracy (model ELTl03; Sartorius, Goettingen, Germany) to determine average berry weight and calculate the average number of berries per cluster. Twenty clusters were randomly collected from each experimental unit, whole-cluster pressed, and the juice was strained through cheesecloth and frozen at $-25{ }^{\circ} \mathrm{C}$ until processing. Before processing, to ensure acids 
were completely redissolved into the solution, the juice was thawed using a warm water bath for $30 \mathrm{~min}$, allowed to equilibrate to room temperature, and shaken to homogenize the sample before analysis of soluble solids, titratable acidity (TA), and pH. The soluble solids content was measured using a digital refractometer with temperature compensation (model PAL-1; Atago USA, Bellevue, WA), and $\mathrm{pH}$ was analyzed using a calibrated $\mathrm{pH}$ meter (sympHony model SB8OPl; VWR, Radnor, PA). Titratable acidity was measured by titrating a $50-\mathrm{mL}$ aliquot of juice against $0.10 \mathrm{M} \mathrm{so-}$ dium hydroxide to a $\mathrm{pH}$ of $8.2 \mathrm{using}$ an automatic titrator (model DL22; Mettler Toledo, Columbus, $\mathrm{OH}$ ). Juice samples from each experimental unit at harvest were also tested for yeast assimilable nitrogen (YAN) using a ChemWell 2910 Multianalyzer (Unitech Scientific, HIan Gardens, CA) and spectrophotometry to test for ammonia and primary amino nitrogen as described by Nisbet et al. (2013).

Winemaking. After yield data were collected at harvest, fruit with more than $30 \%$ of any type of rot was discarded. All remaining fruit from the different replicates for each treatment was whole-cluster pressed using a hydraulic bladder press (Hydro 40 Inox; Zambelli Enotech, Camisano Vicentino, Italy), up to 2 bars of pressure. Juice was treated with $50 \mathrm{mg} \cdot \mathrm{L}^{-1}$ of sulfur dioxide as potassium metabisulfite for microbial control and Lallzyme C (Lallemand, Toulouse, France), a pectinase used to accelerate juice clarification, at $2 \mathrm{~g} \cdot \mathrm{hL}{ }^{-1}$, before settling for $24 \mathrm{~h}$ at $4{ }^{\circ} \mathrm{C}$. Juice from each of the four treatments was then racked into two 5-gal glass carboys to produce two wine replicates per treatment. Juice was inoculated with $0.25 \mathrm{~g} \cdot \mathrm{L}^{-1}$ of Saccharomyces cerevisiae strain EC1118 (Lallemand), rehydrated with Go-Ferm (Lallemand) as per manufacturer's directions. Carboys were moved into a $15{ }^{\circ} \mathrm{C}$ fermentation room and stirred daily. FermAid K (Lallemand) was added at a rate of $0.15 \mathrm{~g} \cdot \mathrm{L}^{-1}$ at the lag phase of fermentation $(\approx 3 \mathrm{~d}$ after inoculation) and after one-third sugar depletion, and diammonium phosphate supplemented after the lag phase to bring the total YAN of juice to 200 ppm total, inclusive of the FermAid $\mathrm{K}$ additions. Wines were fermented to less than $0.5 \%$ residual sugar, confirmed using a Clinitest tablet (Bayer, West Haven, CT). Wines were then racked into clean carboys and stored at $4{ }^{\circ} \mathrm{C}$, with $50 \mathrm{mg} \cdot \mathrm{L}^{-1}$ of sulfur dioxide as potassium metabisulfite added. Wines were not subjected to acid adjustments or malolactic fermentation, were screened for faults, and were manually bottled in 750-mL green glass bottles with natural corks and stored at $4{ }^{\circ} \mathrm{C}$ until wine analysis and sensory evaluation. Wines were not made in 2013 due to the smaller experimental unit size.

Sensory. Wines from 2011 and 2012 were evaluated for aromatic differences 12 and 6 months after bottling, respectively. Wines were sorted by aroma and analyzed using multidimensional sorting analysis using a previously described method (Preszler et al., 2013) for 'Riesling' aroma sorting. Aroma sorting was done by a panel consisting of males and females, ages 21 to 63 years, who were a part of Cornell University faculty, staff, and students who selfreported consuming white wine at least once per month. In 2011 and 2012, 46 and 62 panelists participated, respectively, in the trials. Participants were seated in a fluorescently lit room and separated by white partitions. Wines were served in 30-mL portions at room temperature in clear, tulip-shaped 220-mL wine glasses (International Organization for Standardization, Geneva, Switzerland) with aluminum foil lids. Two fermentation replicates of each under-vine treatment were served, so a total of eight glasses coded with a random three-digit unique identification number were presented to panelists in a randomized order. Panelists were asked to sort wines, by aroma without tasting, into one to four groups, placing wines that were found to be similar by aroma together in the same group. Panelists were instructed to sort wines based on their perceptions of the aromatic properties using their own sorting criteria. There was no rating of wine characteristics and panelists did not receive any advance training to reduce imposed researcher bias and in accordance with the past research (Lawless and Heymann, 1998; Preszler et al., 2013).

Statistics. All vineyard and juice characteristic data were analyzed using JMP® software (version 11.0; SAS Institute, Cary, NC) with precursory analysis to confirm normal distribution and identify outliers. A mixed model analysis of variance was used, with treatment as a fixed variable and replicate number as random. Significance was determined using the Tukey honest significance difference test at a 5\% significance level. To analyze sorting results, wines that were grouped together were given a similarity rating of one and wines not sorted into the same group scored a zero. The sum of the similarity scores for each wine replicate was calculated and similarity square matrix for each vintage was created and analyzed using MDS statistical analysis with $\mathrm{SAS}^{\circledR}$ software (version 8.0; SAS Institute). MDS generates a visual representation of the similarity square matrix, where samples that were paired more frequently together are spatially closer than those not grouped together. The resulting graphical output of the MDS analysis can be used to interpret similarity among samples, even when the underlying attributes are not exactly known. MDS has been previously used for white wine aroma evaluation (Lee and Noble, 2006; Preszler et al., 2013).

\section{Results}

Climate. The daily average temperature and weekly precipitation in Lodi, NY, within $3 \mathrm{~km}$ of the field research site was measured from 2011 through 2013. Using this temperature data, growing degree-day values were calculated using a base of $50{ }^{\circ} \mathrm{F}$. The greatest number of growing degree days $\left(2909{ }^{\circ} \mathrm{F}\right)$ were accumulated in 2012, compared with 2011 $\left(2791^{\circ} \mathrm{F}\right)$ and $2013\left(2792^{\circ} \mathrm{F}\right)$. Total precipitation from 1 May to 31 Oct. was $59.3 \mathrm{~cm}$ in $2011,40.6 \mathrm{~cm}$ in 2012 , and $34.5 \mathrm{~cm}$ in 2013 (New York State Integrated Pest Management Program, 2014).

Cover CROP ESTABlishment. The species comprising the RES treatment were identified at veraison and harvest each year. In the lst year, while other species were present, nearly $100 \%$ of the individual plants present were composed of only two species, common purslane (Portulaca oleracea) and pennsylvania smartweed (Polygonum pensylvanicum) at both veraison and harvest. By the 2 nd and 3rd years of establishment, common purslane and pennsylvania smartweed were still present, but within a more diverse mix of grass and annual species that included smooth crabgrass 
(Digitaria ischaemum), large crabgrass (Digitaria sanguinalis), annual bluegrass (Poa annua), yellow foxtail (Setaria pumilia), lady's thumb (Persicaria maculosa), and common lambsquarters (Chenopodium album). Seeded cover crops were also successfully established in each year of the study, but the same weed species in the RES treatment were identified within BW and ARG treatments in all years.

Soil and petiole analyses. There were no significant differences among treatments for soil nutrient concentrations of potassium, phosphorus, calcium, magnesium, aluminum, iron, and zinc (data not shown; refer to Jordan, 2014), and all values were within recommended ranges for the region (Wolf, 2008). Organic matter content was scored high for all treatments (Gugino et al., 2009), ranging from $5.91 \%$ to $6.85 \%$, and the undervine cover crops were not found to significantly affect organic matter content compared with the herbicide-treated control $(P=0.32)$. Wet aggregate stability scores ranged from $39.5 \%$ to $47.1 \%$ stable aggregates across the four treatments, medium-rated scores for stability (Gugino et al., 2009), and there was no significant difference among treatments $(P=0.39)$. Undervine treatments were not found to have any consistent effect on nitrogen, potassium, phosphorous, calcium, magnesium, manganese, boron, zinc, or copper concentrations within the petioles at veraison (data not shown; refer to Jordan, 2014). While there were no significant differences among treatments, petiole nitrogen was found to be low across all four treatments, ranging from $0.43 \%$ to $0.57 \%$ among treatments in the 3 years of study. Although these concentrations were below the normal recommended values of $0.8 \%$ to $1.2 \%$ for veraison for healthy plant growth (Wolf, 2008), no visual symptoms of nitrogen deficiency or lack of vigor, such as less than ideal values of pruning weights, shoot lengths, or leaf layers, were noted. All other nutrient values were within normal ranges (Wolf, 2008).

Vine water potential. Predawn leaf water potential was quantified once per month on randomly selected precipitation-free nights between June and Aug. 2012 and July and Aug. 2013. The $\Psi_{\text {predawn }}$ values ranged from -0.16 to $-0.29 \mathrm{MPa}$ in 2012 and -0.11 to $-0.24 \mathrm{MPa}$ in
2013. Under-vine cover crops did not affect the $\Psi_{\text {predawn }}$ values with the exception on 6 July 2013 where the $\mathrm{BW}(-0.12 \mathrm{MPa})$ was significantly lower than CON predawn value $(-0.08 \mathrm{MPa}, P=0.046)$, but no other consistent effect or treatment and date interaction was found. The $\Psi_{\text {midday }}$ values were quantified on $6 \mathrm{~d}$ from mid-June until Sept. 2012 and July through Sept. 2013. Measurements were taken on clear days without precipitation, but were otherwise randomly selected throughout the growing season. The $\Psi_{\text {midday }}$ values were similar in both years, with values across the growing season ranging from -0.32 to $-0.57 \mathrm{MPa}$ in 2012 and -0.32 to $-0.53 \mathrm{MPa}$ in 2013. There was no significant treatment or treatment by day interaction effects in 2012 or 2013 on $\Psi_{\text {midday. }}$.

VEGETATIVE GROWTH AND YIELD. Under-vine cover crops did not reduce shoot length or shoot growth rate at any point during the growing season in 2012 or 2013 (data not shown; refer to Jordan, 2014). The EPQA parameters quantifying canopy architecture and light exposure, including occlusion layer number, cluster and leaf exposure layer, and cluster and leaf exposure flux availability, were not found to be significantly different across under-vine treatments in any year of the study (Table 1). Yield components, shoot diameter, pruning weight, and juice characteristics did not vary consistently among treatments (Tables 2 and 3 ). The ARG treatment was found to slightly reduce growth on two occasions. In 2012, ARG yielded 9 to 12 fewer berries per cluster compared with all other treatments $(P=0.006)$. In 2013, ARG reduced average berries per cluster by 20 berries compared with the RES treatment $(P=0.04)$ (Table 2$)$. For all treatments including ARG, the number of clusters, total cluster weight per vine, and average individual berry mass were not significantly different. Under-vine cover crops did not affect soluble solids, TA, $\mathrm{pH}$, or YAN values in any year (Table 3 ).

WINEMAKING AND MULTIDIMENSIONAL SORTING ANALYSIS OF WINE AROMA. A two-dimensional model that met R-squared and stress value criteria was generated using the sorting data, which then was used to create the MDS consensus plots. These plots graphically represent that panelists found differences in wine aroma for the under-vine cover crop treatments for both years (Fig. 1). For 2011, based on their aromatic properties, there was no consistent grouping of wines by treatment. In 2012, the two CON wine replicates were grouped separately from the majority of the under-vine vegetation treatment wines, with one ARG replicate found to be aromatically similar to the two controls.

\section{Discussion}

The annual under-vine cover crops used in this experiment did not generate sufficient competition for water or nutrients to have any consistent effects on vine vegetative growth or yield, even when planted directly in the under-vine row. In previous work, using cover crops in vineyards has been found to reduce soil and/or vine moisture levels and measures of vine vegetative growth and yield (Morlat and Jacquet, 2003; Tesic et al., 2007; Wheeler et al., 2005). Competition for water was insufficient in this study to affect growth because midday stem water potential was consistently above growth-inhibiting values of -0.9 to $-1.2 \mathrm{MPa}$ (Girona et al., 2006; Schultz and Matthews, 1988). The water potentials in this study were similar to previously reported values for wine grape vines in the Finger Lakes region (Centinari et al., 2015; Intrigliolo et al., 2009). The predawn stem water potential values were never lower than $-0.3 \mathrm{MPa}$, suggesting that the plants rehydrate at night and that water was never a growth-limiting resource. Stem water potentials in this range indicate extremely hydrated conditions for grape vines and help to illustrate the moisture-rich conditions of growing wine grapes in the cool and humid northeastern U.S. climate that may prevent cover crops from competing for water and reducing vine growth. Competition for nutrients was also not evident. After 3 years of cover crop establishment, there was no effect of cover crops on petiole nutrient content at veraison, including no reduction in nitrogen content. All treatments had lower than recommended values of nitrogen (Wolf, 2008). However, vines showed no visible symptoms of deficiency, and pruning weights were at recommended 
Table 1. Enhanced point quadrant analysis characteristics of 'Riesling' grapevines at veraison, with different under-vine treatments (UVT) established annually at the start of the growing season from 2011 through 2013 at a commercial vineyard in the Finger Lakes region in Lodi, NY.

\begin{tabular}{|c|c|c|c|c|c|}
\hline UVT $^{\mathbf{z}}$ & $\begin{array}{l}\text { Occlusion } \\
\text { layers (no.) }\end{array}$ & $\begin{array}{c}\text { Cluster } \\
\text { exposure layers }(\text { no. })^{\mathrm{x}}\end{array}$ & $\begin{array}{l}\text { Leaf exposure } \\
\text { layers }(\text { no. })^{\mathrm{x}}\end{array}$ & $\begin{array}{l}\text { Cluster exposure } \\
\text { flux availabilityw }\end{array}$ & $\begin{array}{l}\text { Leaf exposure } \\
\text { flux availability }\end{array}$ \\
\hline \multicolumn{6}{|c|}{$2011^{\mathrm{v}}$} \\
\hline BW & 2.81 & 0.58 & 0.29 & 0.30 & 0.42 \\
\hline $\mathrm{CON}$ & 2.97 & 0.65 & 0.32 & 0.24 & 0.38 \\
\hline RES & 2.94 & 0.68 & 0.29 & 0.33 & 0.44 \\
\hline ARG & 2.72 & 0.92 & 0.39 & 0.15 & 0.38 \\
\hline BW & 3.17 & 0.86 & 0.36 & 0.19 & 0.33 \\
\hline $\mathrm{CON}$ & 3.46 & 0.93 & 0.41 & 0.18 & 0.34 \\
\hline \multirow[t]{2}{*}{ RES } & 3.11 & 0.79 & 0.36 & 0.19 & 0.38 \\
\hline & NS & NS & NS & NS & NS \\
\hline \multirow[t]{2}{*}{ RES } & 2.83 & 0.55 & 0.31 & 0.34 & 0.43 \\
\hline & NS & NS & NS & NS & NS \\
\hline
\end{tabular}

${ }^{\mathrm{z}} \mathrm{ARG}$ = annual ryegrass; $\mathrm{BW}=$ buckwheat $\mathrm{CON}$ = glyphosate sprayed control; RES = resident vegetation.

ycclusion layer number is the number of shade producing contacts (leaves and clusters) at one insertion point in the canopy (Meyers and Vanden Heuvel, 2008).

${ }^{x}$ Cluster or leaf exposure layer is the number of shading layers between cluster or leaf, respectively, and the boundary of the canopy (Meyers and Vanden Heuvel, 2008).

wCluster or leaf exposure flux availability is the percentage, expressed as a decimal, of the above-canopy photo flux that reaches a cluster or leaf (Meyers and Vanden Heuvel, 2008).

"Values are an average of four experimental units for each column consisting of a weighted average by cluster count for the upper and lower fruiting zones of four vines in 2011 and 2012

"Values are an average of four experimental units for each column consisting of a weighted average by cluster count for the upper and lower fruiting zones of two vines in 2013. ${ }^{\mathrm{Ns}}$ Nonsignificant at $P \leq 0.05$ based on a mixed model analysis of variance test conducted on a mixed model with a post-hoc Tukey's honest significant difference test.

values or exceeded them (Wolf, 2008), indicating that nitrogen was not limiting to vine growth at this site.

The cover crop species for this experiment were chosen to introduce competition for water and nutrient resources at different times in the season. Pre-veraison water deficits are known to cause the greatest reduction in vine growth and yield (Matthews and Anderson, 1989). The fruit develops a greater insensitivity to water deficits over time (Matthews and Anderson, 1989), whereas vine growth remains responsive to nitrogen supply throughout the season (Keller, 2005). BW rapidly establishes and goes to seed by the time of veraison in the Finger Lakes region, but ARG exhibits continuing growth into the late summer and fall (Bjorkman and Shail, 2010). The ARG treatment has slightly fewer berries per cluster than some of the other treatments in the 2nd and 3rd year. We cannot attribute these differences to water stress because the ARG treatment was not fully established during berry set and the water potential was equal to the other treatments.
As a grass, ARG continued to grow late in the season, even after veraison, unlike the other broad-leaf and earlier season species in other treatments. A possible carryover effect from the lateseason growth or allelopathic interactions may explain the few instances of reduced vine growth in the ARG treatment.

ARG and BW are shallow rooted species (Bjorkman and Shail, 2010), and grapevines have the potential to extend and/or use existing roots deeper in the profile to avoid competition. Grapevines are known to have one of the proportionally deepest rooting distributions with rooting depths of up to $6 \mathrm{~m}$ (Smart et al., 2006). In this experiment, vines were grafted onto SO4 rootstock that is capable of producing deep roots $(>80-90 \mathrm{~cm})$ in different soil types (Morlat and Jacquet, 1993). Cover crops have been found to reduce vine rooting near the soil surface and encouraged deeper rooting patterns in wine grapes (Morlat and Jacquet, 2003). 'Cabernet franc' vines in the Finger Lakes region shed fine roots growing within the root zones of BW and ARG cover crops, favoring root growth in other, less competitive parts of the soil profile (Centinari et al., 2015). In this study, the nearly 20 -year-old vines in this dryfarmed 'Riesling' vineyard were likely able to overcome any competition effects from the comparatively shallow root systems of the cover crops. Likely, the well-developed and extensive rooting system of the SO4 rootstock was able to exploit the less competitive areas of the soil profile, similar to what was seen in the work by Centinari et al. (2015).

Under-vine cover crops in a humid climate did reduce vegetative growth on 2- to 4-year-old vines (Hatch et al., 2011), but newly established vineyards with less developed rooting systems would be more susceptible to the effects of vegetation in the vineyard floor. A perennial cover crop used as living mulch in a nearly 30 -yearold vineyard in a Continental climate was not found to have an effect on vine yields or cluster size (DeVetter et al., 2015). The lack of effect of under-vine cover crops on shoot growth and yield 
Table 2. Yield and vine growth components of 'Riesling' grapevines with different under-vine treatments (UVT) established annually at the start of the growing season from 2011 through 2013 at a commercial vineyard in the Finger Lakes region in Lodi, NY.

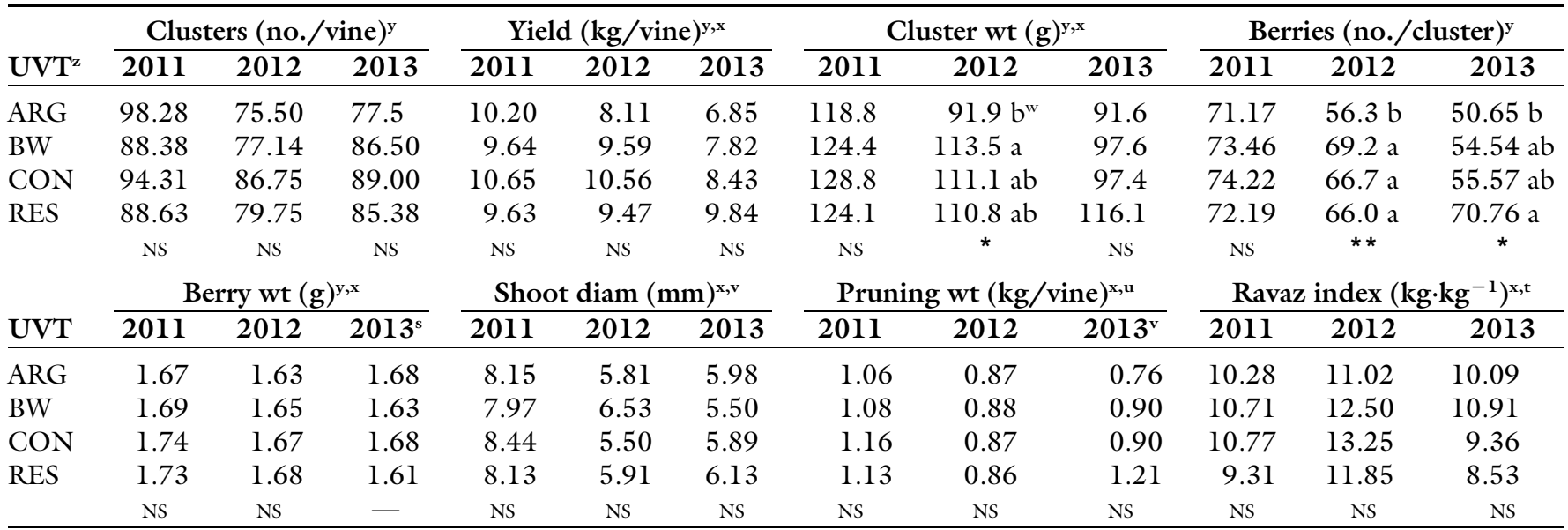

${ }^{2} \mathrm{ARG}=$ annual ryegrass; $\mathrm{BW}=$ buckwheat $\mathrm{CON}=$ glyphosate sprayed control; $\mathrm{RES}=$ resident vegetation.

'Data were collected within $1 \mathrm{~d}$ of commercial harvest, 5 Oct. 2011, 22 Sept. 2012, and 3 Oct. 2013.

${ }^{\mathrm{x}} \mathrm{l} \mathrm{kg}=2.2046 \mathrm{lb} ; \mathrm{l} \mathrm{g}=0.0353 \mathrm{oz} ; 1 \mathrm{~mm}=0.0394$ inch.

"Mean separation in columns based on by Tukey's honest significant difference (HSD) at $P \leq 0.05$

'Data were collected at 50\% veraison, 20 Aug. 2011 , 15 Aug. 2012, and 28 Aug. 2013.

"Data were collected in the last week of March of the following year from the year of harvest. Pruning weights only included the dormant cane mass left on the vine after in-season hedging.

${ }^{t}$ Ravaz values were calculated for each vine within the experimental unit before statistical analysis, using the yield per vine (kg) at harvest divided by the pruning weights of dormant canes per vine $(\mathrm{kg})$, taken in winter in March of the following year.

${ }^{\mathrm{s}}$ For 2013 , berry weights are the measure of one replicate.

Ns, ${ }^{* *},{ }^{* * *}$ Nonsignificant or significant at $P \leq 0.05,0.01$, or 0.001 , respectively, based on a mixed model analysis of variance test conducted on a mixed model with a post hoc Tukey's HSD test.

Table 3. Juice characteristics from 'Riesling' grape clusters, collected within $1 \mathrm{~d}$ of commercial harvest, on 5 Oct. 2011,22 Sept. 2012, and 3 Oct. 2013, with different under-vine treatments (UVT) established annually at the start of the growing season at a commercial vineyard in the Finger Lakes region in Lodi, NY.

\begin{tabular}{|c|c|c|c|c|c|c|c|c|c|c|c|c|}
\hline \multirow[b]{2}{*}{ UVT $^{\mathbf{z}}$} & \multicolumn{3}{|c|}{ Soluble solids (\%) } & \multicolumn{3}{|c|}{ TA $\left(g \cdot L^{-1}\right)^{y}$} & \multicolumn{3}{|c|}{$\mathrm{pH}$} & \multicolumn{3}{|c|}{ YAN $\left(\mathrm{mg} \cdot \mathrm{L}^{-1}\right)^{\mathrm{y}}$} \\
\hline & 2011 & 2012 & $2013^{x}$ & 2011 & 2012 & $2013^{x}$ & 2011 & 2012 & $2013^{x}$ & 2011 & 2012 & $2013^{x}$ \\
\hline ARG & 16.6 & 17.1 & 17.5 & 6.76 & 8.23 & 7.5 & 3.31 & 3.00 & 2.97 & 52 & 32 & 32 \\
\hline $\mathrm{CON}$ & 16.2 & 16.4 & 17.3 & 7.12 & 8.33 & 8.0 & 3.38 & 2.98 & 2.90 & 75 & 43 & 49 \\
\hline \multirow[t]{2}{*}{ RES } & 16.5 & 17.1 & 18.0 & 7.03 & 8.28 & 8.5 & 3.29 & 2.99 & 2.95 & 52 & 40 & 36 \\
\hline & NS & NS & - & NS & NS & - & NS & NS & - & NS & NS & - \\
\hline
\end{tabular}

${ }^{\mathrm{z}} \mathrm{ARG}=$ annual ryegrass; $\mathrm{BW}=$ buckwheat $\mathrm{CON}=$ glyphosate sprayed control; $\mathrm{RES}=$ resident vegetation; $\mathrm{TA}=$ titratable acidity; $\mathrm{YAN}=$ yeast assimilable nitrogen.

${ }^{\mathrm{y}} \mathrm{l} \mathrm{g} \cdot \mathrm{L}^{-1}=0.1 \% ; \mathrm{l} \mathrm{mg} \cdot \mathrm{L}^{-1}=1 \mathrm{ppm}$.

In 2013 , juice characteristics are the measure of one replicate.

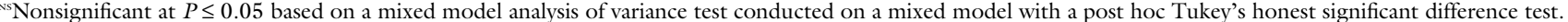

components in this study is in accordance with previous work done in the Finger Lakes examining the effects of under-vine cover crops in a mature 'Cabernet franc' vineyard (Centinari et al., 2015). Conditions in the Finger Lakes may allow mature grapevines to overcome competition that may be induced by under-vine cover crops, as opposed to studies in warm, dry climates where growth and yield reductions were reported in rain-fed vineyards (Monteiro and Lopes, 2007; Morlat and Jacquet, 2003; Sicher et al., 1993).

In order for under-vine cover crops to be adopted in cool climates as a replacement for using herbicides to maintain bare ground, the impacts on vineyard management and cost of production must be considered. On a vigorous site or during a wet growing season, cover crops may grow to the height of the fruiting zone and dense vegetation underneath vines may be undesirable for disease management and fruit exposure. To mitigate some of these potential drawbacks, mowing under the vine could be used to control cover crop growth. There are commercially available under-vine mowers that could be used to maintain the height of under-vine cover crops in traditional single-fruiting zone training systems with upright shoot growth. In this study on a Scott Henry system, a trellis rake wire that rested below the lower fruiting zone was used to sweep the shoots of the lower half of the canopy upward and secure them temporarily upright, to enable mowing under the vine to restrict cover crop height after harvest. Karl (2015) calculated the cost of establishment and maintenance of RES and annually seeded white clover (Trifolium repens) cover crops to be only $\$ 84$ and $\$ 169$ per hectare, respectively. If fruit yield is not impacted, such as in this study and in the study by Centinari et al. (2015), cost of production could be maintained or even reduced for the grower with adoption of an under-vine cover crops compared with a conventional herbicide, 


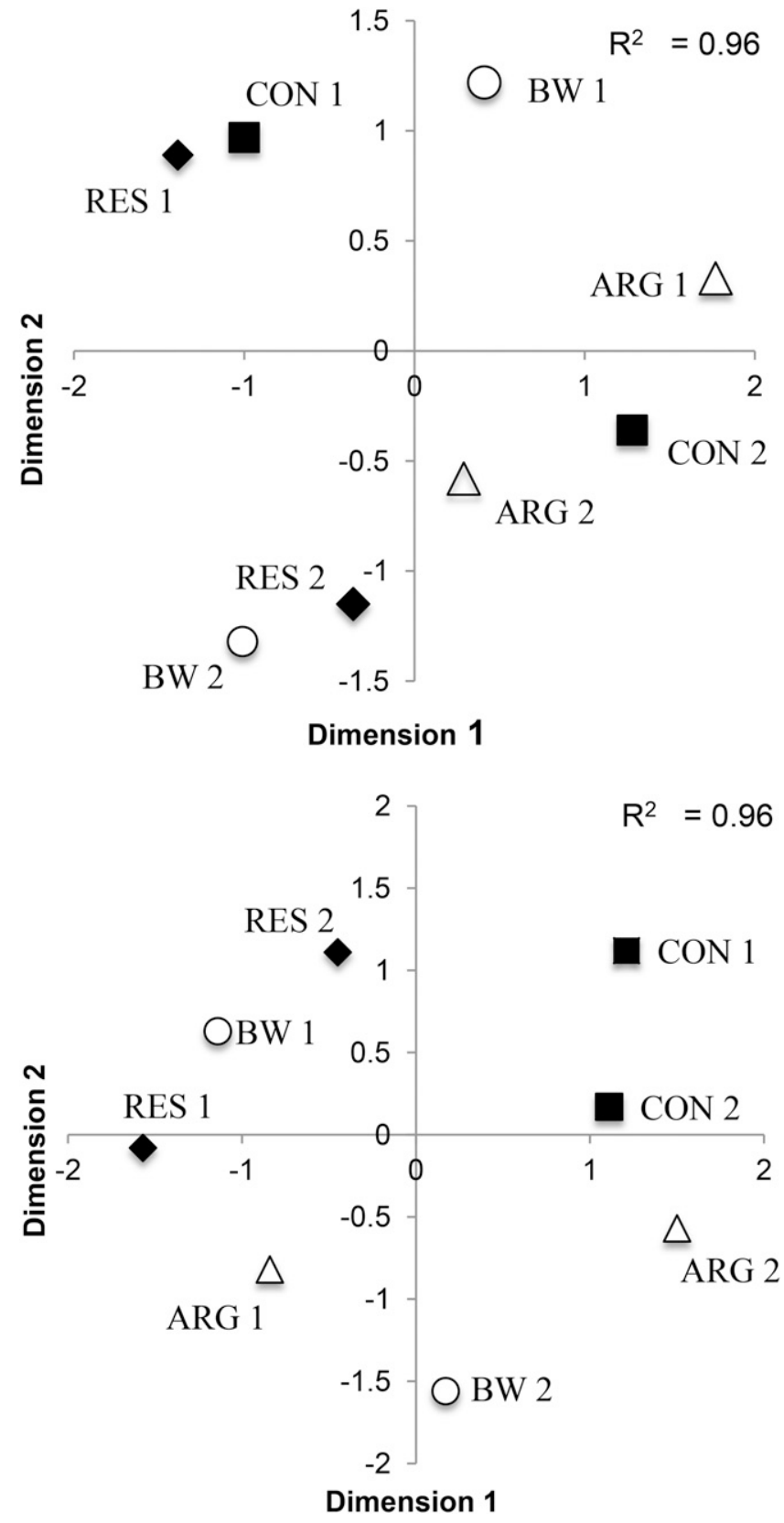

Fig. 1. Two dimensional consensus plots of aroma similarity ratings of 'Riesling' wines from 2011 (top) and 2012 (bottom) from the under-vine treatments (ARG = annual ryegrass, $\mathrm{BW}=$ buckwheat, $\mathrm{CON}=$ glyphosate sprayed control, $\mathrm{RES}=$ resident vegetation). The number after the treatment indicates fermentation replicate number.

even if mowing was required. However, if cover crops reduced vine growth and yield such as in the study by $\operatorname{Karl}(2015)$, the revenue per acre would be reduced. In a particularly dry year or in drought conditions where soil moisture may be depleted, water may become limiting to vine production, and there may be a greater risk for under-vine cover crops to induce sufficient competition to lower yields and revenue. Current season conditions and impacts on management must be considered for under-vine cover crops to provide an economical alternative to herbicide use.

Similar to several previous studies looking at interrow (Pool et al., 1990; Tesic et al., 2007) and intrarow cover crops (Centinari et al., 2015; Giese et al., 2014), this study found under-vine cover crops had no significant impacts on juice characteristics including soluble solids, $\mathrm{TA}, \mathrm{pH}$, and YAN. Interestingly, wines produced from vines with different species of annual under-vine cover crops were perceived to be different by aroma from each other in both years of the study and from those grown with the herbicide control in the 2nd year (Fig. 1). Previous work has shown that cover crops can impact compounds important to wine aroma (Reynolds et al., 2005; Xi et al., 2011), but there was no clear cause of the perceived differences in wine aroma by any of the measured variables in this experiment.

Light exposure in the canopy is known to affect aromatics in 'Riesling', where increased canopy shading decreased concentrations of $\mathrm{C}_{13}$ norisoprenoids like 1,1,6-trimethyl-1,2dihydronapthalene (TDN) in 'Riesling' (Meyers et al., 2013). It may be possible that the use of under-vine cover crops induced differences during the pre-veraison period, when light can impact the concentration of TDN and other aroma compounds at harvest (Kwasniewski et al., 2010; Meyers et al., 2013). EPQA measurements were not taken until veraison and therefore would be unable to detect any differences earlier in the season.

Although there were no differences found in the water and nutrient measurements made in this study, water and nutrient availability is known to impact aromatic precursor synthesis. While no statistically significant differences were found among treatments for midday stem water potentials, differences as small as $0.3 \mathrm{MPa}$ have been found to result in different juice phenolic concentrations (Matthews and Anderson, 1989). In such wellhydrated conditions, possibly the small reduction in plant water status, like seen at the one measured predawn value in 2013, may have resulted in vine metabolic differences that altered aroma compound precursor production. Similarly, there was no detectable difference in petiole nitrogen content at veraison, but samples were not collected until veraison, and nitrogen deficiency during the growing season has been found to decrease wine aroma (Choné et al., 2006). Nitrogen uptake may have varied earlier in the growing season and affected aromatic compound synthesis, but by veraison, nitrogen content was low for all treatments because of site conditions and therefore differences may have been undetectable at that time. The moisture-rich conditions and timing of nutrient measures 
may have prohibited the causal differences for the varying wine aromas from being detected.

\section{Conclusion}

The long-standing practice of using herbicides beneath vines in coolclimate 'Riesling' wine grape vineyards is derived from the expectation that under-vine vegetation would induce a level of competition that would have a detrimental impact on grapevines, as it sometimes has been found to in drier regions. Previous work in other climates and varieties had shown that using cover crops in the under-vine row may be a viable alternative to maintaining bare soil vineyards, but cover crops would need to be established annually in the under-vine row to accommodate hilling up in the northeastern U.S. climate. Contrary to the hypothesis that annual undervine cover crops may alleviate excessive growth, conditions of the northeastern United States did not generate sufficient competition for water or nutrients to impact 'Riesling' vines. Over 3 years, using annually established under-vine cover crops did not reduce vine growth or yields in a mature 'Riesling' vineyard, but did impact the aromas of wines made from the different under-vine treatments. Since the under-vine cover crops did not have a detrimental effect on yield or vine growth, planting annual cover crops may offer an economic and environmentally sustainable alternative to maintaining bare ground with herbicide in cool and humid climate vineyards.

\section{Literature cited}

Bjorkman, T. and J. Shail. 2010. Cornell cover crop guide. 10 Jan. 2014.<http:// covercrops.cals.cornell.edu>.

Centinari, M., J.E. Vanden Heuvel, M. Goebel, M.S. Smith, and T.L. Bauerle. 2015. Root-zone management practices impact above and below-ground growth in Cabernet Franc grapevines. Aust. J. Grape Wine Res. doi: 10.1111/ajgw.12162.

Choné, X., V. Lavigne-Cruège, T. Tominaga, C. van Leeuwen, C. Castagnède, C. Saucier, and D. Dubourdieu. 2006. Effect of vine nitrogen status on grape aromatic potential: Flavor precursors (systeine conjugates), glutathione and phenolic content in Vitis vinifera L. cv. Sauvignon Blanc grape juice. J. Intl. Sci. Vigne Vin 40:1-6.
DeVetter, L.W., C.A. Dilley, and G.R. Nonnecke. 2015. Mulches reduce weeds, maintain yield, and promote soil quality in a continental-climate vineyard. Amer. J. Enol. Viticult. 66:54-64.

Giese, G., T.K. Wolf, C. Velasco-Cruz, L. Roberts, and J. Heitman. 2014. Cover crop and root pruning impacts on vegetative growth, crop yield components, and grape composition of Cabernet Sauvignon. Amer. J. Enol. Viticult. 66:212-226.

Girona, J., M. Mata, J. del Campo, A. Arbones, E. Bartra, and J. Marsal. 2006. The use of midday leaf water potential for scheduling deficit irrigation in vineyards. Irr. Sci. 24:115-127.

Gugino, B.K., O.J. Idowu, R.R. Shindelbeck, H.M. van Es, D.W. Wolfe, B.N. Moebius-Clune, J.E. Thies, and G.S. Abawi. 2009. Cornell soil health assessment training manual. Cornell Univ., Geneva, NY.

Hatch, T.A., C.C. Hickey, and T.K. Wolf. 2011. Cover crop, rootstock, and root restriction regulate vegetative growth of Cabernet Sauvignon in a humid environment. Amer. J. Enol. Viticult. 62:298-311.

Holt, J.S. 1992. History of the identification of herbicide-resistant weeds. Weed Technol. 6:615-620.

Intrigliolo, D.S., A.N. Lakso, and R.M. Piccioni. 2009. Grapevine cv. 'Riesling' water use in the northeastern United States. Irr. Sci. 27:253-262.

Jordan, L.M. 2014. Evaluating the effects of using annually established under-vine cover crops in northeastern Riesling vineyards. MS Thesis, Cornell Univ., Ithaca, NY.

Karl, A. 2015. Impact of under-vine management on vine growth, yield, fruit composition and wine sensory analyses of Cabernet franc. MS Thesis, Cornell Univ., Ithaca, NY.

Keller, M. 2005. Deficit irrigation and vine mineral nutrition. Amer. J. Enol. Viticult. 56:267-283.

Kliewer, W.M. and N.K. Dokoozlian. 2005. Leaf area/crop weight ratios of grapevines: Influence on fruit composition and wine quality. Amer. J. Enol. Viticult. 56:170-181.

Kwasniewski, M.T., J.E. Vanden Heuvel, B.S. Pan, and G.L. Sacks. 2010. Timing of cluster light environment manipulation during grape development affects $\mathrm{C}_{13}$ norisoprenoid and carotenoid concentrations in 'Riesling'. J. Agr. Food Chem. 58:6841-6849.

Landry, D., S. Dousset, and F. Andreux. 2006. Leaching of oryzalin and diuron thorugh undisturbed vineyard soil columns under outdoor conditions. Chemosphere 62:1736-1747.

Lawless, H. and H. Heymann. 1998. Sensory evaluation of food. Chapman Hall, New York, NY.

Lee, S.J. and A.C. Noble. 2006. Use of partial least squares regression and multidimensional scaling on aroma models of California chardonnay wines. Amer. J. Enol. Viticult. 57:363-370.

Martinez-Casanovas, J.A. and I. SanchezBosch. 2000. Impact assessment of changes in land use/conservation practices on soil erosion in the Penedès-Anoia vineyard region (NE Spain). Soil Tillage Res. 57:101-106.

Matthews, M.A. and M.M. Anderson. 1989. Reproductive development in grape (Vitis vinifera L.): Responses to seasonal water deficits. Amer. J. Enol. Viticult. 40:52-59.

Meyers, J.M., G.L. Sacks, and J.E. Vanden Heuvel. 2013. Glycosylated aroma compound responses in 'Riesling' wine grapes to cluster exposure and vine yield. HortTechnology 23:581-588.

Meyers, J.M. and J.E. Vanden Heuvel. 2008. Enhancing the precision and spatial acuity of point quadrat analyses via calibrated exposure mapping. Amer. J. Enol. Viticult. 59:425-431.

Monteiro, A. and C.M. Lopes. 2007. Influence of cover crop on water use and performance of vineyard in Mediterranean Portugal. Agr. Ecosyst. Environ. 121:336-342.

Morlat, R. and A. Jacquet. 1993. The soil effects on the grapevine root system in several vineyards of the Loire Valley (France). Vitis 32:35-42.

Morlat, R. and A. Jacquet. 2003. Grapevine root system and soil characteristics in a vineyard maintained long-term with or without interrow sward. Amer. J. Enol. Viticult. 54:1-7.

New York State Integrated Pest Management Program. 2014Network for environment and weather applications weather data. 1 Aug. 2014. <http:// newa.cornell.edu/>.

Nisbet, M.A., T.E. Martinson, and A.K. Mansfield. 2013. Preharvest prediction of yeast assimilable nitrogen in Finger Lakes Riesling using linear and multivariate modeling. Amer. J. Enol. Viticult. 64:485-494.

Pool, R.M., R.M. Dunst, and A.N. Lakso. 1990. Comparison of sod, mulch, cultivation, and herbicide floor management-practices for grape production in nonirrigated vineyards. J. Amer. Soc. Hort. Sci. 115:872-877. 
Preszler, T., T.M. Schmit, and J.E. Vanden Heuvel. 2013. Cluster thinning reduces the economic sustainability of Riesling production. Amer. J. Enol. Viticult. 64:333-341.

Reynolds, A.G., P. Parchomchuk, R. Berard, A.P. Naylor, and E. Hogue. 2005. Gewurztraminer grapevines respond to length of water stress duration. Intl. J. Fruit Sci. 5:75-94.

Schultz, H.R. and M.A. Matthews. 1988. Resistance to water transport in shoots of Vitis vinifera L.: Relation to growth at low water potential. Plant Physiol. 88:718-724.

Sicher, L., A. Dorigoni, and G. Stringari. 1993. Soil management effects on nutritional status and grapevine performance.
Mineral Nutr. Deciduous Fruit Plants 383:73-82.

Smart, R.E., J.K. Dick, I.M. Gravett, and B.M. Fisher. 1990. Canopy management to improve grape yield and wine quality: Principles and practices. South African J. Enol. Viticult. 11:3-17.

Smart, R.E. and M. Robinson. 1991. Sunlight into wine: A handbook for winegrape canopy management. Winetitles, Adelaide, Australia.

Smart, D.R., E. Scwass, A.N. Lakso, and L. Morano. 2006. Grapevine rooting patterns: A comprehensive analysis and a review. Amer. J. Enol. Viticult. 57:89-104.

Tesic, D., M. Keller, and R.J. Hutton. 2007. Influence of vineyard floor management practices on grapevine vegetative growth, yield, and fruit composition. Amer. J. Enol. Viticult. 58:1-11.
U.S. Department of Agriculture. 2013. Welcome to web soil survey. 1 Aug. $2014<$ http://websoilsurvey.nrcs. usda.gov $/>$.

Wheeler, S.J., A.S. Black, and G.J. Pickering. 2005. Vineyard floor management improves wine quality in highly vigorous Vitis vinifera 'Cabernet Sauvignon' in New Zealand. N.Z. J. Crop Hort. Sci. 33:317-328

Wolf, T.K. 2008. Wine grape production guide for eastern North America. Natural Resources Agr. Eng. Serv., Ithaca, NY.

Xi, Z., Y. Tao, L. Zhang, and H. Li. 2011. Impact of cover crops in vineyard on the aroma compounds of Vitis vinifera L. cv Cabernet Sauvignon wine. Food Chem. 127:516-522. 